\title{
REUSED TYRE POLYMER FIBRE FOR FIRE-SPALLING MITIGATION
}

\author{
Shan-Shan Huang ${ }^{\mathrm{a}}$, Harris Angelakopoulos ${ }^{\mathrm{b}}$, Kypros Pilakoutas ${ }^{\mathrm{a}}$, Ian Burgess ${ }^{\mathrm{a}}$ \\ ${ }^{a}$ Department of Civil \& Structural Engineering, University of Sheffield, UK \\ ${ }^{\mathrm{b}}$ Twincon Ltd., UK
}

\begin{abstract}
Polypropylene fibres (PPF) are used in concrete principally to reduce plastic shrinkage cracking, but also to prevent explosive spalling of concrete exposed to fire. In the EU alone, an estimated 75,000 tonnes of virgin PPF are used each year. At the same time an estimated 63,000 tonnes of polymer fibres are recovered from end-of-life tyres, which are agglomerated and too contaminated with rubber to find any alternative use; currently these are mainly disposed of by incineration. The authors have initiated a study on the feasibility of reusing tyre polymer fibres in fresh concrete to mitigate fire-induced spalling. If successful, this will permit replacement of the virgin PPF currently used with a reused product of equal or superior performance. A preliminary experimental investigation is presented in this paper. High-strength concrete cubes/slabs have been tested under thermo-mechanical loading. This study has shown promising results; the specimens with the tyre polymer fibres have shown lower vulnerability to spalling than those of plain concrete.
\end{abstract}

Keywords:Spalling, Fire, Concrete, Reused Tyre Polymer Fibre

\section{INTRODUCTION}

Concrete is normally considered inherently fire resistant, due to its low thermal conductivity and non-combustibility. However, it does suffer from fire-induced spalling, which is one of the most complex and hence poorly understood phenomena in fire engineering (Fletcher et al., 2007,Bisbyet al., 2014). Fire-induced spalling can be explosive and it can occur at temperatures as low as $200{ }^{\circ} \mathrm{C}$. It can significantly reduce the fire resistance of concrete structures, due to (1) reduction in crosssection area of structural elements; (2) loss of thermal protection to the internal steel reinforcement. Fire-induced spalling may cause loss of life and huge economic losses, as exemplified by catastrophic tunnel fires (SP Technical Research Institute of Sweden, 2012) in recent decades. For example, the Channel Tunnel fires in 1996, 2006 and 2008 caused severe damages to the structure. After the 1996 fire, the concrete lining over about half a mile was destroyed, causing $£ 200 \mathrm{M}$ worth of damage, which resulted in the closure of the tunnel for seven months (The Guardian, 2008). The maximum depth of concrete damage to the tunnel linings, caused by spalling, reached $100 \%$ (Khoury, 2000) exposing the tunnel to the potential disastrous risk of flooding.

In recently years, there have been many developments in concrete technology and modern construction now uses high-performance, high-strength and self-compacting concretes. However, a major drawback of these concretes is their increased propensity for fire-induced spalling and, hence, there is a need for research to understand their performance in fire (Bisbyet al., 2014,Khoury, 2000). Small doses of PPF are often introduced into fresh concrete, principally to reduce early plastic shrinkage cracking in the first few days after casting. This has also been found to improve resistance to spalling of the hardened concrete if exposed to fire.

In the EU alone, an estimated 63,000 tonnes of polymer fibres are generated each year as a byproduct of the recycling (for recovering rubber) of tyres (Jose, 2010). These fibres are currently a negative-value waste; they are agglomerated and contaminated with rubber, and are generally disposed of by incineration (subject to a gate fee and transportation costs). The storage of these fibres is a problem, since they are flammable and very often trigger fires in tyre recycling facilities (Figure 1); they are also easily carried away by wind and pollute the surrounding environment. This paper presents a preliminary experimental study, examining the feasibility of reusing tyre polymer 
fibres in fresh concrete to mitigate fire-induced spalling, as part of ANAGENNISI (2015), a European collaborative project exploring the reuse of tyre components in concrete. With further research as well as the development of processing techniques, the eventual target is to facilitate the replacement of manufactured PPF currently used in concrete with a reused product of equal or superior performance.

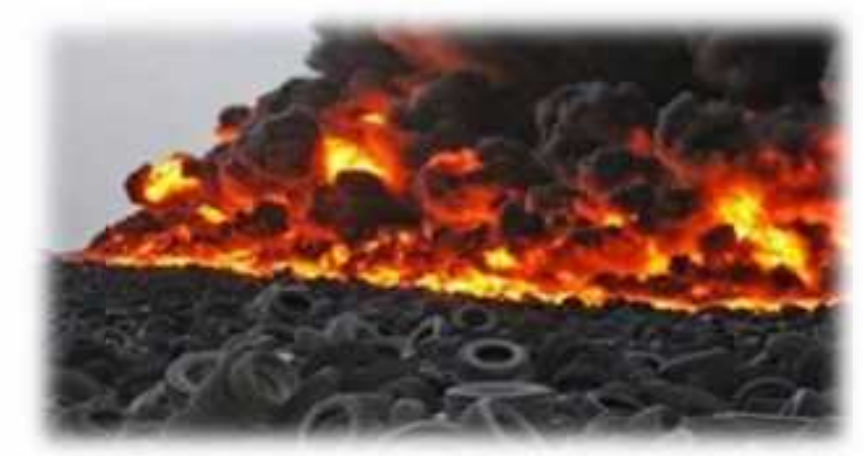

Fig. 1 Fire in a tyre recycling plant (Source: www.pyrolassist.com)

\section{PRELIMINARY EXPERIMENTAL INVESTIGATION}

\subsection{Fibre Processing for Reuse}

Polymer reinforcement in tyres is of high specification and durability. However, the way it is currently extracted leaves it contaminated with rubber and too tangled to be reused as a construction material. There are no techniques for removing rubber contamination and separating tangled filaments. Laboratory trials at small scale have been carried out and shown that the screening technique (using vibrating sieves) can work to remove rubber dust and coarse particles, as shown in Figure 2. In addition, manual separation during integration (into concrete) is sufficient to enable a uniform dispersal of the fibres in concrete for laboratory testing.
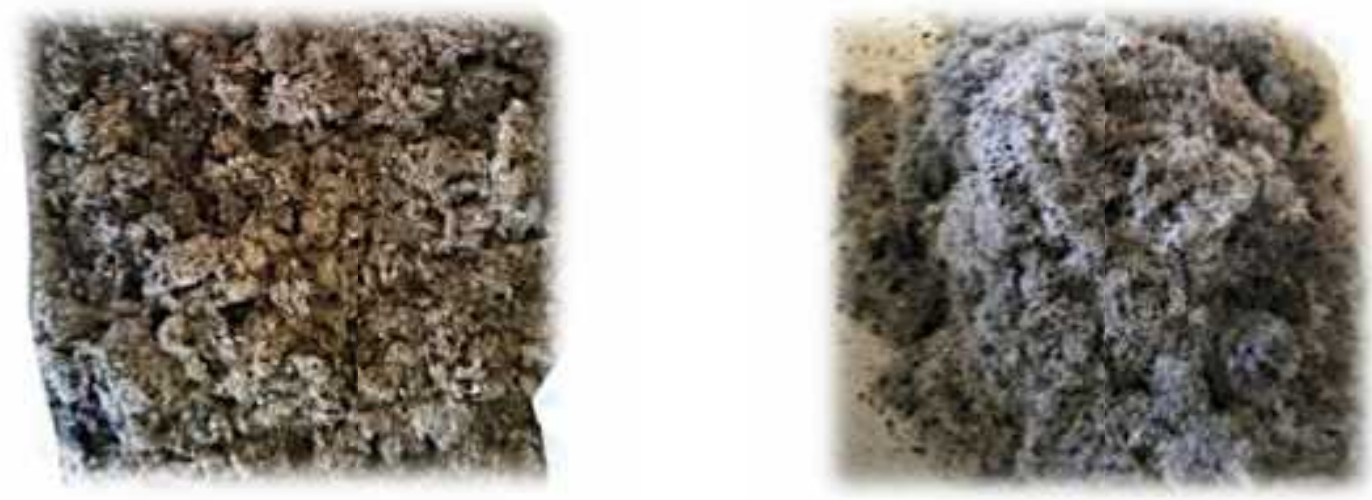

Fig. 2 Tyre polymer fibres before (left) and after (right) processing for reuse

\subsection{Fire-Spalling Tests}

The effect of Reused Tyre Polymer Fibre (RTPF) on a high-strength and self-compacting concrete mix has been studied. In particular, the fire-spalling risk of mixes with and without RTPF has been investigated through 12 high-temperature slab tests under axial compressive stress (Figure 3(b)). Four concrete mixes were tested: Mix 1 (control mix) plain concrete; Mix 2 with $1 \mathrm{~kg} / \mathrm{m}^{3} \mathrm{RTPF}$; Mix 3 with $2 \mathrm{~kg} / \mathrm{m}^{3}$ RTPF, based on the EC2 (CEN, 2004) recommended PPF dosage; and Mix 4 with $7 \mathrm{~kg} / \mathrm{m}^{3} \mathrm{RTPF}$. All tests were conducted in triplicate.

Trial testing on 12 unloaded $100 \mathrm{~mm}$ cubes was also carried out (Figure 3(a)). The same plain concrete control mix, as well as a mix with $7 \mathrm{~kg} / \mathrm{m}^{3} \mathrm{RTPF}$, was adopted. Six repeats per mix were adopted. Heating was applied by a single-headed blowtorch. 


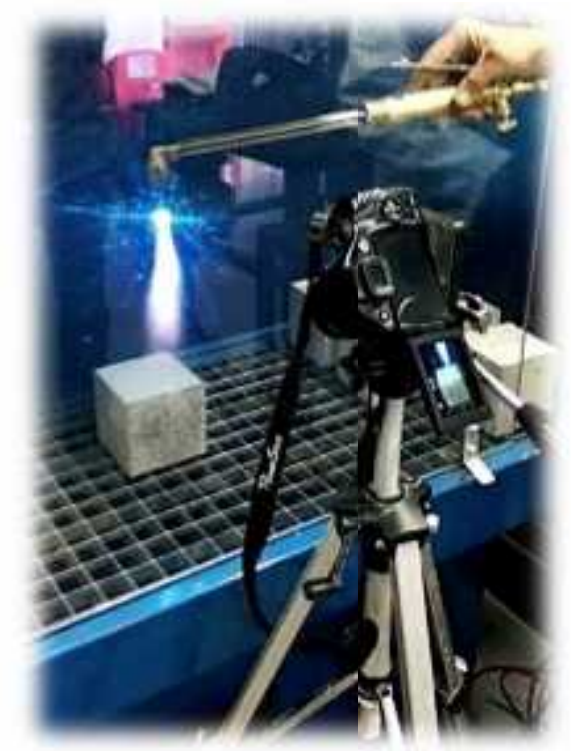

(a)

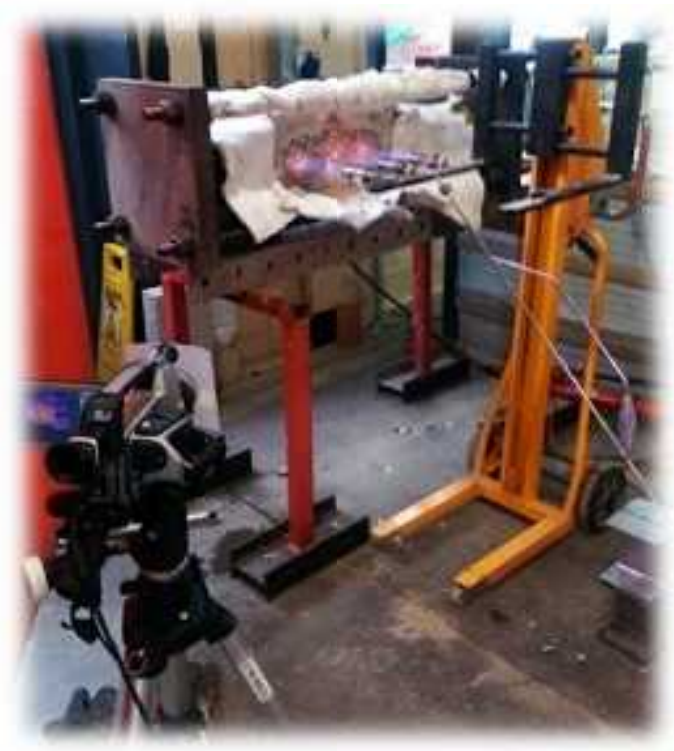

(b)

Fig. 3 Test setup (a) cube tests, (b) slab tests

A typical high-strength (70MPa) and self-compacting concrete mix (not considering the difference in fibre dosages) was adopted. The slabs were $500 \times 220 \mathrm{~mm}$ x $100 \mathrm{~mm}$. Additional100 mm cubes were also cast for moisture content and strength tests at the time of spalling tests. All specimens were cured to BS EN 12390 Part 2 (BSI, 2009).

The slabs were heated using a three-headed blowtorch. Trial tests were conducted to determine the distance between the blowtorch head and the heated surface of the slabs, to produce an initial heating rate as close to that of a hydrocarbon fire (CEN, 2002) as possible. The distance of the blowtorch from the sample remained constant throughout all tests. A thermal imaging camera was used to measure the temperature distribution throughout the heated surface of a specimen. Thermocouples were cast into the slab, at mid-depth $(50 \mathrm{~mm}$ from the heated surface), at the centre of heating of each blowtorch head.

Before heating, the slabs were axially loaded at $10.5 \mathrm{MPa}, 15 \%$ of the ambient-temperature compressive (cube) strength. During heating, the thermal expansion along the loaded axis was restrained and the increase in the compressive stress was recorded throughout testing; the loaded edges of the specimen were protected so that the jack was not affected by heating.

\section{RESULTS AND DISCUSSION}

For the 12 trial tests on unloaded cubes, two out of the six plain concrete specimens spalled, whereas all six specimens with RTPF did not spall. One example pair (left: with RTPF; right: plain concrete) is shown in Figure 4.

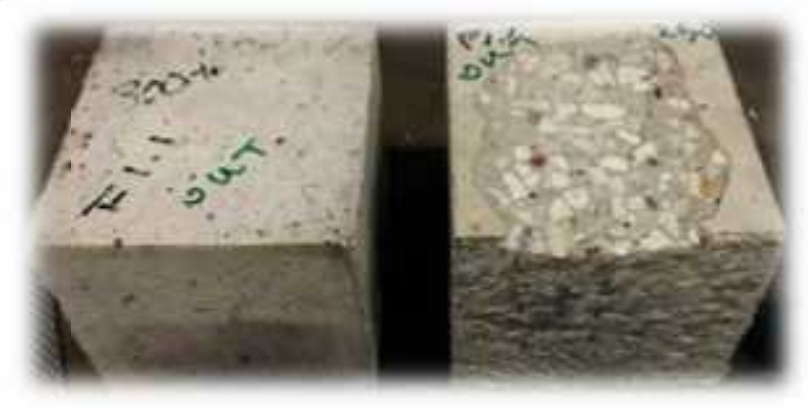

Fig. 4 Aftermath of the cube tests

Table 1 shows the aftermath of the 12 loaded slab tests. 
Table 1 Aftermath of the slab tests

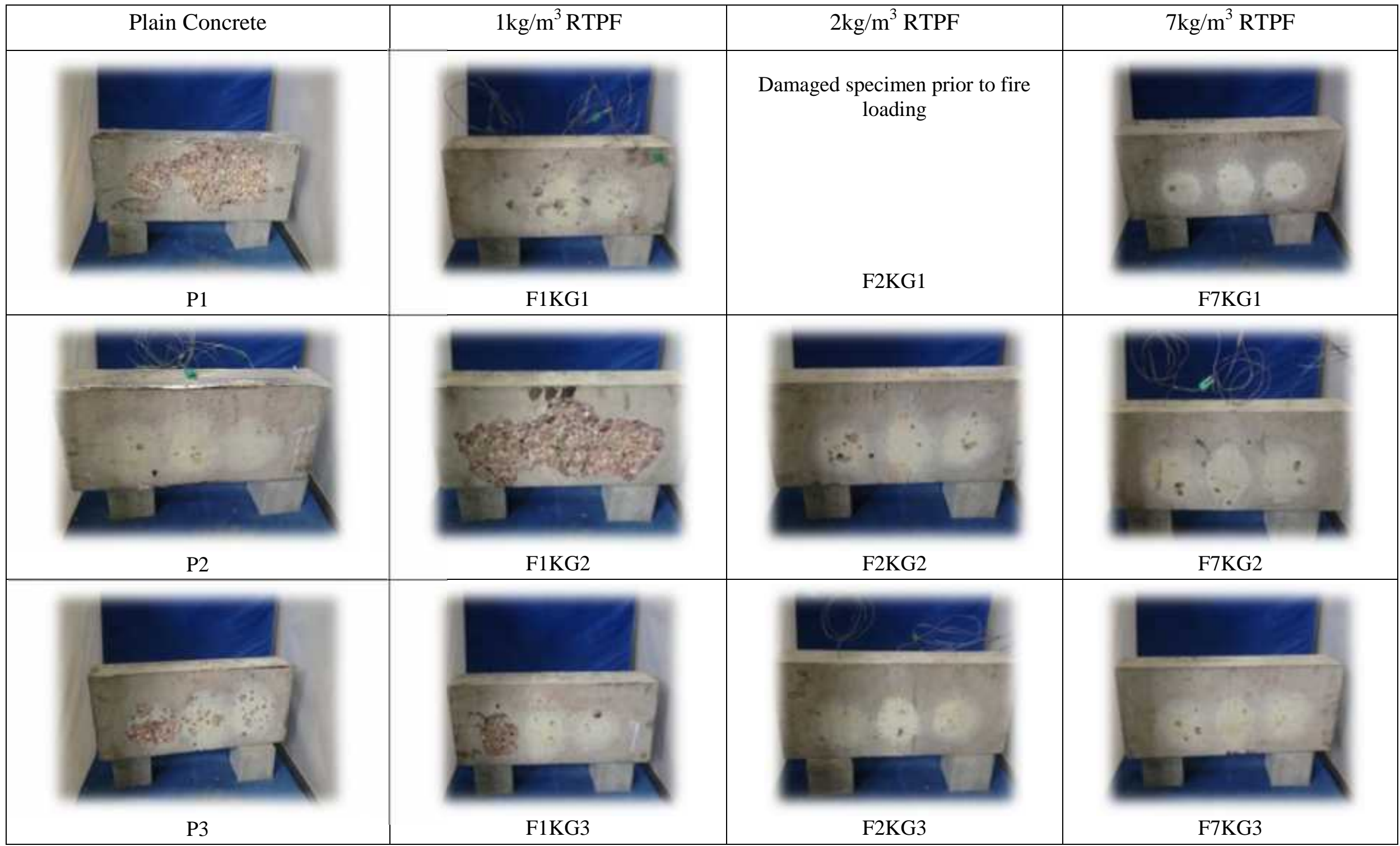


Two of the three plain concrete slabs and two of the three slabs with low RTPF dose $\left(1 \mathrm{~kg} / \mathrm{m}^{3}\right)$ experienced various degrees of spalling. In particular, specimens P1, F1KG2 and F1KG3 spalled heavily. None of the six specimens with medium and high RTPF doses $\left(2 \mathrm{~kg} / \mathrm{m}^{3}\right.$ and $\left.7 \mathrm{~kg} / \mathrm{m}^{3}\right)$ spalled. These are encouraging initial results, showing the potential of RTPF for fire-spalling mitigation. It has been expected that a higher dose of reused fibres than that of manufactured fibres (i.e. $2 \mathrm{~kg} / \mathrm{m}^{3}$ of PPF as recommended by EC2) will be required to achieve equal performance. However, the results of this series of testing have indicated the opposite. Hence, more research is needed before the effectiveness of RTPF in preventing spalling can be confirmed.

The compressive strength at the time of each spalling test was approximately $70 \mathrm{MPa}$, as expected. Their moisture contents were between $2.1 \%$ and $3.4 \%$. EC2 states that spalling is unlikely to occur when the moisture content in concrete is lower than $3 \%$ by mass. However, most of the spalled specimens had moisture contents below 3\%, indicating the potential risk borne by high-strength concretes.

A thermal camera was used to measure the temperature distribution across the heating surface. Figure 5 shows a typical image taken by the thermal camera during heating. Figure 6 plots the maximum surface temperature-time relationship of F1KG2 in comparison with that of the hydrocarbon fire, indicating a reasonable match between the two. The temperature plotted in this figure is the average of the temperatures at points SP01, SP02 and SP03, as marked in Figure 5. Sudden drops of surface temperature due to the occurrence of spalling were captured. These data will be used for inverse thermal analysis to quantify the degree (depth, area, etc.) of spalling.

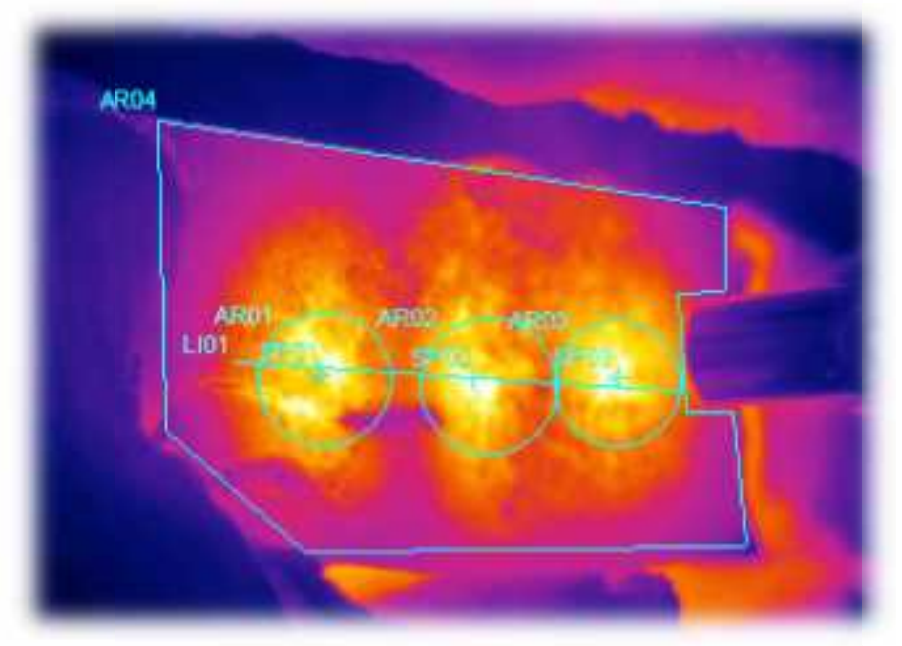

Fig. 5 Surface temperature measured by thermal imaging camera

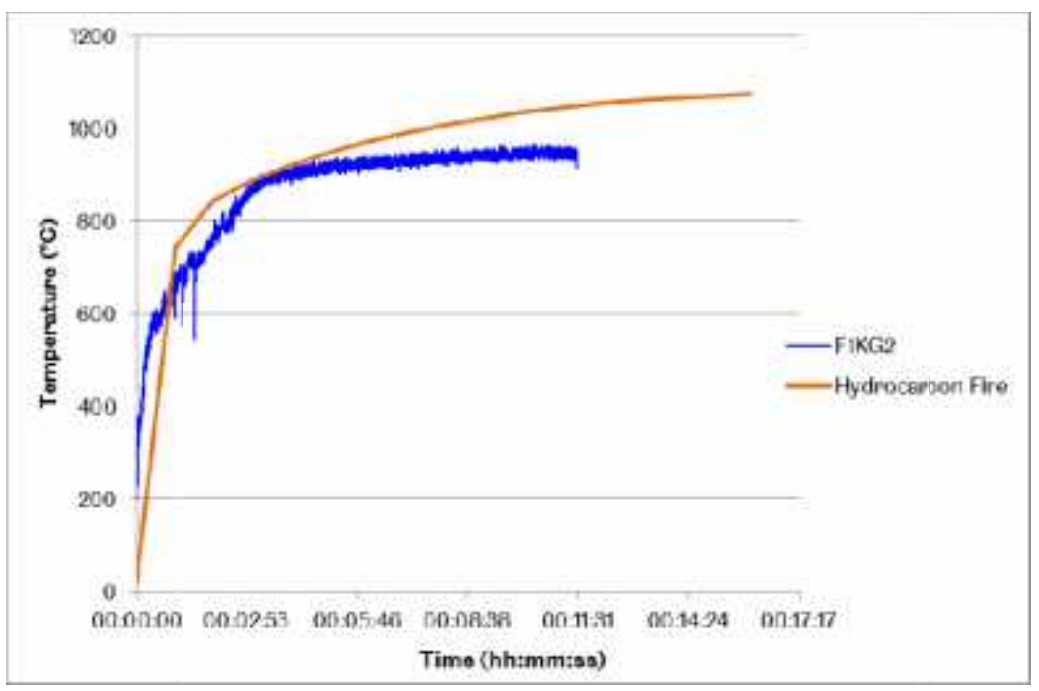

Fig. 6 Surface temperature of F1KG2 vs. hydrocarbon fire 


\section{CONCLUSIONS}

This paper presents a proof-of-concept experimental study, exploring the potential of reusing waste polymer fibre extracted from end-of-life tyres in concrete to prevent fire-induced spalling. Promising initial results have been achieved; all specimens with reused tyre polymer fibre at a dose equal to or above $2 \mathrm{~kg} / \mathrm{m}^{3}$ (dose of virgin polypropylene fibre for spalling mitigation suggested by the Eurocode) did not spall. Further research and the development of processing techniques are needed and have been planned. The eventual target is to facilitate the replacement of manufactured polypropylene fibre currently used in concrete with a reused product for the development of sustainable fire-spalling resistance concrete.

\section{ACKNOWLEDGMENTS}

The research leading to these results has received funding from the European Union Seventh Framework Programme [FP7/2007- 2013] under grant agreement $n^{\circ}$ 603722. The authors also gratefully acknowledge the contribution of Grace Waterman to the experimental work.

\section{REFERENCES}

Fletcher I., Welch S., Torero J., Carvel R., Usmani A. 2007. Behaviour of Concrete Structures in Fire. Thermal Science, 11 (2), p. 37-52.

Bisby L., Mostafaei H., Pimienta P. 2014. State-of-the-Art on Fire Resistance of Concrete Structure Structure-Fire Model Validation. Retrieved from http://www.nist.gov/el/fire_research/upload/MicrosoftWord-NIST-White-Paper-on-Concrete_DRAFT_25-03-14-Copy.pdf

SP Technical Research Institute of Sweden.2012. Fire-Spalling of Self-Compacting Concrete. Retrieved from http://www.tunneltalk.com/TunnelTech-May12-Concrete-fire-spalling.php

The Guardian. 2008. Channel Tunnel Fire Worst in Service's History. Retrieved from http://www.theguardian.com/uk/2008/sep/12/transport.channeltunnel1

Khoury G. 2000. Effect of Fire on Concrete and Concrete Structures. Progress in Structural Engineering and Materials, 2 (4), p. 429-447.

San Jose. 2010. Global Tire Shipments to Reach 1.7 Billion Units by 2015, According to a New Report by Global Industry Analysts, Inc. Retrieved http://www.prweb.com/releases/tires_OEM/replacement_tire/prweb4545704.htm

Anagennisi Project. 2015. Retrieved from http://www.anagennisi.org/

CEN. 2004. Eurocode 2: Design of Concrete Structures - Part 1-2: General Rules - Structural Fire Design. Brussels: European Committee on Standardization.

BSI. 2009. BS EN 12390-2 Testing hardened concrete. Making and curing specimens for strength tests.

CEN. 2002. Eurocode 1: Actions on Structures. General Actions. Actions on Structures Exposed to Fire. Brussels: European Committee on Standardization. 